\title{
Untrimmed Placental Weight
}

National Cancer Institute

\section{Source}

National Cancer Institute. Untrimmed Placental Weight. NCI Thesaurus. Code C117339.

The weight of the placenta after delivery, with membranes intact and some length of the umbilical cord attached, to the nearest gram, before draining the blood from the specimen. 